\title{
Palatalização das oclusivas alveolares [t] e [d] com a semivogal [j] em contexto anterior na cidade de Maceió
}

\author{
Almir Almeida Oliveira ${ }^{1}$
}

Alan Jardel Oliveira ${ }^{2}$

Aldir Santos de Paula ${ }^{3}$

\section{Resumo}

Este trabalho tem como objetivo, sob a ótica da Sociolinguística Variacionista (LABOV, 2008 [1972]), investigar os processos fonéticos/fonológicos da palatalização progressiva das oclusivas alveolares com a semivogal $[j]$ em contexto anterior, como em palavras do tipo oi $[t]$ o e doi[dz]o, produzidos no Português Brasileiro falado em Maceió, contrapondo os dados linguísticos coletados com as variáveis externas (idade, sexo e escolaridade) e internas (contexto seguinte, acento, tamanho da palavra, vozeamento e fronteira lexical), a fim de identificar possiveis condicionantes de uso das variantes. Utilizando-se do método bipotéticodedutivo, os resultados obtidos apontam para a interação social entre as variáveis sociais idade e escolaridade, indicando que os informantes mais jovens são os maiores favorecedores desse processo de palatalização quando têm baixos indices de escolarização, ao passo que apresentam comportamento linguístico inverso, inibindo a palatalização, quando possuem maiores niveis de escolaridade. Assim, bá indícios de que as formas palatalizadas padecem de uma valoração social negativa.

Palavras-chaves: Sociolinguística Variacionista. Palatalização progressiva. Maceió

\footnotetext{
${ }^{1}$ Doutor em Letras e Linguística pela Universidade Federal de Alagoas. Professor assistente da Universidade Estadual de Alagoas.

2 Doutor em Linguística Teórica e Descritiva pela Universidade Federal de Minas Gerais. Professor adjunto da Universidade Federal de Alagoas.

${ }^{3}$ Doutor em Linguística pela Universidade Estadual de Campinas. Professor associado da Universidade Federal de Alagoas.
} 


\section{Introdução}

Este trabalho busca investigar o fenômeno da palatalização progressiva das oclusivas alveolares com a semivogal [j] em posição de contexto anterior como uma característica do português moderno falado na capital alagoana e como os fatores linguísticos e extralinguísticos se relacionam com os processos de palatalização, condicionando seus usos, inclusive observando se a variação é estável ou se trata de uma mudança em curso.

Pelo processo de palatalização, o português integra consoantes palatais que não pertenciam à fonologia do latim clássico, mas que surgiram, ao que muitos estudos indicam, pela mesma motivação, ou seja, pela presença de um segmento vocálico ou fricativo de natureza palatal em suas proximidades (NEUSCHRANK; MATZENAUER, 2012), de modo que a palatalização mantém, como particularidade de realização, a presença de um gatilho fonético com minudências palatais.

O estudo da palatalização tem sido fundamental para o estabelecimento de determinadas regras fonéticas/fonológicas conhecidas e produzidas hoje nesta língua, do mesmo modo que ainda pode fornecer pistas dos processos evolutivos que o português sofre no momento, bem como dos prováveis estabelecimentos linguísticos futuros, apontando para as possíveis mudanças decorrentes da atual variação linguística.

A palatalização é um fenômeno comum e bastante recorrente em línguas latinas, embora a sua motivação progressiva seja mais escassa. No Brasil, as realizações progressivas da palatalização das oclusivas alveolares [t] e [d] se dá apenas em algumas regiões do Nordeste e, de acordo com Cardoso (1993 apud MOTA; ROLEMBERG, 1997, p. 132), apresenta uma expansão que atinge todo o litoral nordestino.

Há poucos trabalhos que tratam deste fenômeno no Brasil, como Mota e Rolemberg (1997), que estudaram, a partir de dados do NURC-Salvador, a palatalização das oclusivas alveolares em situações formais de fala e diálogos informais; Souza Neto (2014), em Aracaju, que buscou a correlação da variante palatalizada com a classe social do informante; Henrique e Hora (2012), em João Pessoa, que apresentam a distribuição das formas variantes palatalizadas de acordo com as variáveis idade, sexo e escolaridade do informante; e Oliveira (2017) em Maceió, que constatou que embora a palatalização progressiva das oclusivas alveolares receba valor negativo na comunidade de fala, essa valoração social afeta 
distintamente o processo, a depender do segmento fonético que antecede a oclusiva. Seus resultados apontam que a palatalização em contexto de semivogal, como em palavras do tipo "oito" e "doido", tem maior peso negativo que em contexto de fricativa, como em formas lexicais do tipo "gosto".

Desse modo, esta pesquisa vem preencher uma importante lacuna teórica nos estudos linguísticos sobre palatalização, pois se trata de uma pesquisa inédita que busca investigar especificamente a distribuição das variantes palatalizadas no processo de palatalização progressiva com semivogal [j] em contexto anterior e aferir como os condicionantes externos e linguísticos afetam distintamente este processo de palatalização.

Para tanto, este artigo apresenta breves considerações acerca de conceitos fundamentais da Sociolinguística, mas ainda cabíveis de discussões e que são fundamentais para o tratamento dos dados, como a noção de comunidade de fala, valoração linguística e identidade, deixando nítido o caminho teórico trilhado. Ademais, aponta as particularidades da palatalização das oclusivas alveolares realizadas em Maceió através de análise estatística dos dados, revelando como as variáveis sociais estão correlacionadas às variáveis linguísticas.

\section{Sociolinguística Variacionista}

A maior empreitada da Sociolinguística Variacionista não tem sido apenas relacionar quantitativamente os aspectos internos da língua com fatores externos - até porque apenas números não dão uma explicação efetiva às questões basilares -, mas notar que todos os dados estatísticos resultantes dessa relativização social-linguística apontam para o fator abstrato da identidade. É justamente a partir da noção de prestígio, que está intrinsecamente relacionada com a ideia de identidade, que se dá o jogo de valores, influenciando na decisão sobre o que permanece na língua e o que é descartado.

Foi isto que ficou evidente quando Labov (2008 [1972]) pesquisou os falantes nativos da ilha de Martha's Vineyard e notou que os falantes que mantinham a alta centralização da vogal /a/ eram justamente as pessoas mais velhas ou aquelas que demonstravam um sentimento de maior apego à ilha e se identificavam com ela, preservando hábitos e costumes locais. Sem dúvidas, a percepção de prestígio e estigma que rodeia as variantes linguísticas 
condiciona as escolhas do falante, dependendo do status social ao qual o falante está almejando e do grupo social ao qual compartilha traços de identificação pessoal.

Já no escopo propriamente sociolinguístico, o prestígio pode ser mensurado com base na ocupação (prestígio do indivíduo, atributos de sua reputação e de seu posto social) e na atitude (prestígio como conduta, abalizado pelo uso de formas e posturas social e culturalmente valorizadas e conferido a partir da interação entre membros de distintos grupos). Nesse domínio, distingue-se também entre prestígio vertical ou externo (entre classes ou grupos sociais, influenciando, por exemplo, a imitação de condutas de classes mais altas por aquelas de classes mais baixas) e horizontal ou interno (no interior de cada classe ou grupo social, influenciando, por exemplo, a propagação de inovações ou mudanças linguísticas) (RONCARATI, 2008, p. 47).

Eis evidentemente um ponto, embora crucial para os desenvolvimentos da sociolinguística variacionista, bastante delicado: pois, do ponto de vista da exatidão científica - que predomina no modelo positivista de produzir conhecimento -, como mensurar a identificação do falante, e consequentemente a percepção de prestígio ou estigma, com as formações sociais que o circunda?

A variação sociolinguística é o meio principal pelo qual o social está inserido na linguagem. Para entender como a variação funciona, temos de nos preocupar com a natureza do significado social que ela traz e com os mecanismos pelos quais a variação passa a ser dotada de significado. Mais particularmente, precisamos examinar o uso da variação de perto, para entender como (e em que medida) ela é usada para expressar sentidos locais e pessoais (ECKERT, 2004, p. 51).

A negociação ativa da relação de um indivíduo com as estruturas sociais é que fornece os valores sociais de identidade, na medida em que essa negociação é sinalizada através da linguagem e de outros meios semióticos. Fatores como sexo, origem, idade, ser brasileiro, argentino, etc. devem ser considerados como construções sociais, de modo que os indivíduos devem ser vistos como agentes inscritos em uma gama de práticas sociais através das quais constroem suas identidades.

O curioso é observar que a identidade, neste nível, apresenta características bilaterais, pois ao mesmo tempo em que o falante, a partir de suas escolhas linguísticas, revela uma identidade individual de acordo com a comunidade de fala a qual pertence, define os traços que podem identificar essa mesma comunidade.

Labov (2008 [1972]) prega que é o valor atribuído pelo grupo de indivíduos a essa 
comunidade de fala que lhe confere certa homogeneidade, bem como sua identificação no âmbito das diversidades da língua. Assim, os falantes devem compartilhar traços linguísticos de valor que sejam diferentes dos outros grupos, ter uma alta frequência de comunicação entre si e apresentar as mesmas normas e atitudes em relação à linguagem.

\begin{abstract}
Além de valores conscientes em relação à língua, os falantes de uma mesma comunidade de fala compartilham, inconscientemente, aspectos essenciais do sistema linguístico - as regras gramaticais -, sendo que os indivíduos adquirem tal sistema sem que eles possam escolher falar deste ou daquele jeito (SEVERO, 2008, p. 8).
\end{abstract}

A comunidade de fala pode ser melhor compreendida como resultante da negociação ativa da relação de um indivíduo com as estruturas sociais mais amplas, na medida em que essa negociação é sinalizada através da linguagem e de outros meios semióticos. Dessa forma, estabelece-se a identidade de uma comunidade de fala, bem como do falante que nela está conscientemente inserido.

Aliás, Labov (2008 [1972]) reconhece que em nível de aquisição de linguagem há uma inconsciência por parte do falante que não escolhe por se inserir em uma língua ou qualquer uma de suas variações, mas defende que este falante tem consciência da comunidade de fala a qual participa e de seu prestígio social. Afinal, "os mecanismos usuais da sociedade produziram diferenças sistemáticas entre certas instituições ou pessoas, e essas formas diferenciadas foram hierarquizadas em status ou prestígio por acordo geral" (LABOV, 1972 [2008], p. 64)

A sociolinguística variacionista tem permitido a investigação das relações entre as práticas sociais - em toda a amplitude que o termo possa permitir - às atitudes linguísticas dos falantes, observando, entre outras coisas, como a noção subjetiva de identidade - atrelada aos valores sociais distintivos - tem interferido na dinâmica linguística e direcionado os caminhos da variação e mudanças linguísticas, como pode ser verificado nos estudos na ilha de Martha's Vineyard (LABOV, 2008 [1972]), na cidade de Newfoundland, no Canadá (CLARKE, 1997), na ilha de British Isles, no Reino Unido (TRUDGILL, 1984), entre outros.

Afinal, de acordo com Cristófaro Silva et al (2012):

Podemos afirmar que o percurso que cada mudança linguística segue não é linear e depende de fatores diversos, inclusive os fatores sociais e pessoais. Uma vez que um determinado padrão esteja em mudança, várias forças de 
instabilidade podem interagir para que tal mudança siga caminhos não previsíveis. Assim, momentos de instabilidade e reorganização de padrões fonológicos de mudança podem ser observados (CRISTÓFARO SILVA et al., 2012, p. 69).

A variação linguística está indubitavelmente atrelada às atividades sociais dos falantes, em toda sua esfera de valores, crenças, hábitos e atitudes, sendo talvez, a língua, o elemento social mais sensível às exteriorizações de comportamento do indivíduo. As marcas sociais de valores chegam à língua em toda sua dimensão natural, desde os aspectos externos da discursividade, aos fragmentos linguísticos tipicamente estruturais da sintaxe, da morfologia e da fonética-fonologia.

Nas pesquisas sociolinguísticas, os grupos de fatores sociais básicos como idade, sexo e escolaridade apresentam condicionamentos às escolhas linguísticas dos falantes, revelando pistas da valoração social cultivada no interior da comunidade de fala, que contribuem para o desenvolvimento e estabelecimento de aspectos subjetivos da identidade do falante.

Assim, a presente pesquisa busca, a partir do estabelecimento da cidade de Maceió como Comunidade de fala investigada, identificar a alternância variacional entre as formas oclusivas [t] e [d] e palatalizadas [t $]$ e [d3] no processo de palatalização progressiva em contexto de semivogal, considerando que a escolha por qualquer uma dessas formas linguísticas envolve questões de valoração social e identificação subjetiva do falante, o que, consequentemente, revela pistas do processo de variação e indica se há uma variação estável ou mudança em curso.

\section{Coleta e tratamento dos dados}

A coleta dos dados para este trabalho foi realizada de acordo com as orientações metodológicas da Sociolinguística Variacionista, tendo como precursor Labov (2008 [1972]) e sendo rediscutida por Campoy e Almeida (2005), Sankoff (1988) e, no Brasil, por Tarallo (1997), Mollica e Braga (2003) e outros.

Para a realização desta pesquisa, foram entrevistadas 48 pessoas estratificadas por sexo, masculino e feminino; idade, em três faixas que variam entre 18 e 35 anos, 36 e 55 anos e 56 e 80 anos; e escolaridade, em quatro níveis de educação, distribuídos em baixa 
escolaridade, ensino fundamental, ensino médio e ensino superior. Como critério para participar desta pesquisa, os colaboradores deveriam ser nascidos em Maceió, ou ter vindo para esta cidade com até cinco anos de idade e não ter morado mais de seis meses fora dela.

Todos os colaboradores foram voluntários e permitiram a gravação e a utilização dos dados, assinando o Termo de Consentimento Livre e Esclarecido - TCLE ${ }^{4}$. Para a realização destas entrevistas, utilizou-se um gravador digital de áudio Coby CXR 190, que permitiu gravar um total de 970 minutos de conversação com os 48 colaboradores, resultando uma média de 20':23" (vinte minutos e vinte e três segundos) por pessoa entrevistada. Foram coletados dados de fala espontânea em ambiente fonológico de realização das oclusivas alveolares /t/ e /d/, antecedidas pela semivogal [j] em situações de fronteira e não fronteira lexical, obtendo realizações linguísticas como as visíveis na figura 1:

\begin{tabular}{l|l|l}
\hline Sequência linguística & Transcrição fonética & Colaborador \\
\hline A mudança de prefeito & [a mu.'dã.se di pre.fej.t]v] & $1 \mathrm{BCF}^{2}$ \\
Ter mais cuidado & [te majs kuj.'dza.dv] & $1 \mathrm{MBF}$ \\
Foi tudo flores & [foj.'t]u.du 'flo.fis] & $1 \mathrm{BBM}$ \\
Já sai daqui & [3a saj.,dza.'ki] & $1 \mathrm{BAF}$ \\
\hline
\end{tabular}

Figura 1: tabela de palatalização das oclusivas alveolares em contexto de semivogal [j] em Maceiós.

Após realizadas as etapas de coleta e transcrições dos dados, foram observados os possíveis padrões de realização da palatalização das oclusivas alveolares /t/ e /d/. O cuidado, assim, foi em garantir o cruzamento das variáveis sociais, escolaridade, idade e sexo e as variáveis linguísticas, com a forma palatalizada ou não das oclusivas alveolares em seus diferentes contextos de realização, a fim de notar se há ou não algum modo de condicionamento social às escolhas linguísticas dos falantes acerca dessas variantes linguísticas palatalizadas.

A fim de estabelecer a relação entre as variáveis sociais e linguísticas e notar os condicionamentos externos dos fenômenos linguísticos, foi feita a codificação dos dados e sua consequente análise estatística. Para a realização da análise estatística dos dados desta

${ }^{4} \mathrm{O}$ TCLE desta pesquisa foi aprovado pelo comitê de ética em pesquisa com o número de CAAE: b15231013.4.0000.5013.

${ }^{5} \mathrm{O}$ código se refere à idade, sexo e escolaridade do informante. 
pesquisa foi utilizado o pacote de programa $\mathrm{R}$, em sua versão 3.3.1, desenvolvido para Microsoft Windows XP ou versão mais recente.

O R possui uma enorme quantidade de procedimentos estatísticos em milhares de pacotes livremente disponíveis na internet e que podem ser carregados opcionalmente. [...] Existem dezenas de interfaces para o R. Algumas exigem a memorização de numerosos comandos; outras oferecem uma interface com vários botões e itens de menu clicáveis (AQUINO, 2014, p. 3).

Nesta pesquisa foi utilizada a interface do RStudio, que é um dos vários ambientes de desenvolvimento integrado (IDE) do $\mathrm{R}$ e funciona a partir da execução de scripts computacionais, apresentando funções para distribuição de probabilidade, testes estatísticos e geração de gráficos (GRIES, 2013). Uma das vantagens em se fazer a análise quantitativa no $\mathrm{R}$, é que além de permitir a utilização do mesmo modelo estatístico dos programas convencionais, o que garante, consequentemente a mesma fidedignidade dos dados, é possível analisar variáveis contínuas e numéricas em um mesmo modelo e mais facilmente realizar testes de interação entre variáveis.

\section{Resultados}

Para realizar as análises das variáveis externas e internas em um ambiente linguístico no qual a semivogal [j] se encontra em posição de contexto anterior às oclusivas alveolares /t/ e /d/, inicialmente, é criado um grupo de dados contendo 2047 realizações linguísticas, das quais 418 apresentam palatalização das oclusivas alveolares. Estes dados estão estratificados quanto às variáveis sociais escolaridade, idade, sexo e as variáveis linguísticas contexto seguinte, acento, tamanho da palavra, fronteira lexical e vozeamento.

A fim de garantir a isonomia da pesquisa, são realizados testes de significância das variáveis, que indicam a probabilidade de (não) significância da variável para o processo de palatalização das oclusivas alveolares em contexto de semivogal.

O teste, ao comparar o modelo completo - com todas as variáveis da pesquisa - com o modelo sem a variável acento, traz o valor de probabilidade em 0.1423 , acima do valor convencional de 0.05 , o que não permite descartar a hipótese nula de os modelos serem 
iguais. Não havendo comprovação estatística de que os modelos são distintos, é mantido o modelo mais simples, neste caso o que não tem a variável acento.

De igual modo, são realizados testes de interação entre as variáveis sociais investigadas, resultando no p-valor de $1.784 \mathrm{e}-10$ para as variáveis idade e escolaridade, o que autoriza a leitura de que a probabilidade de assumir os dois modelos, com interação e sem interação, como estatisticamente idênticos é extremamente baixa, conduzindo ao descarte da hipótese nula e à admissão da hipótese alternativa de que os modelos não têm o mesmo peso significativo, de modo que para estas variáveis sociais é possível afirmar que a interação é produtiva e provoca efeitos na variável dependente.

A interação entre as variáveis idade e escolaridade em relação ao processo de palatalização das oclusivas alveolares no contexto de semivogal fica mais perceptível quando se analisa o gráfico de dispersão:

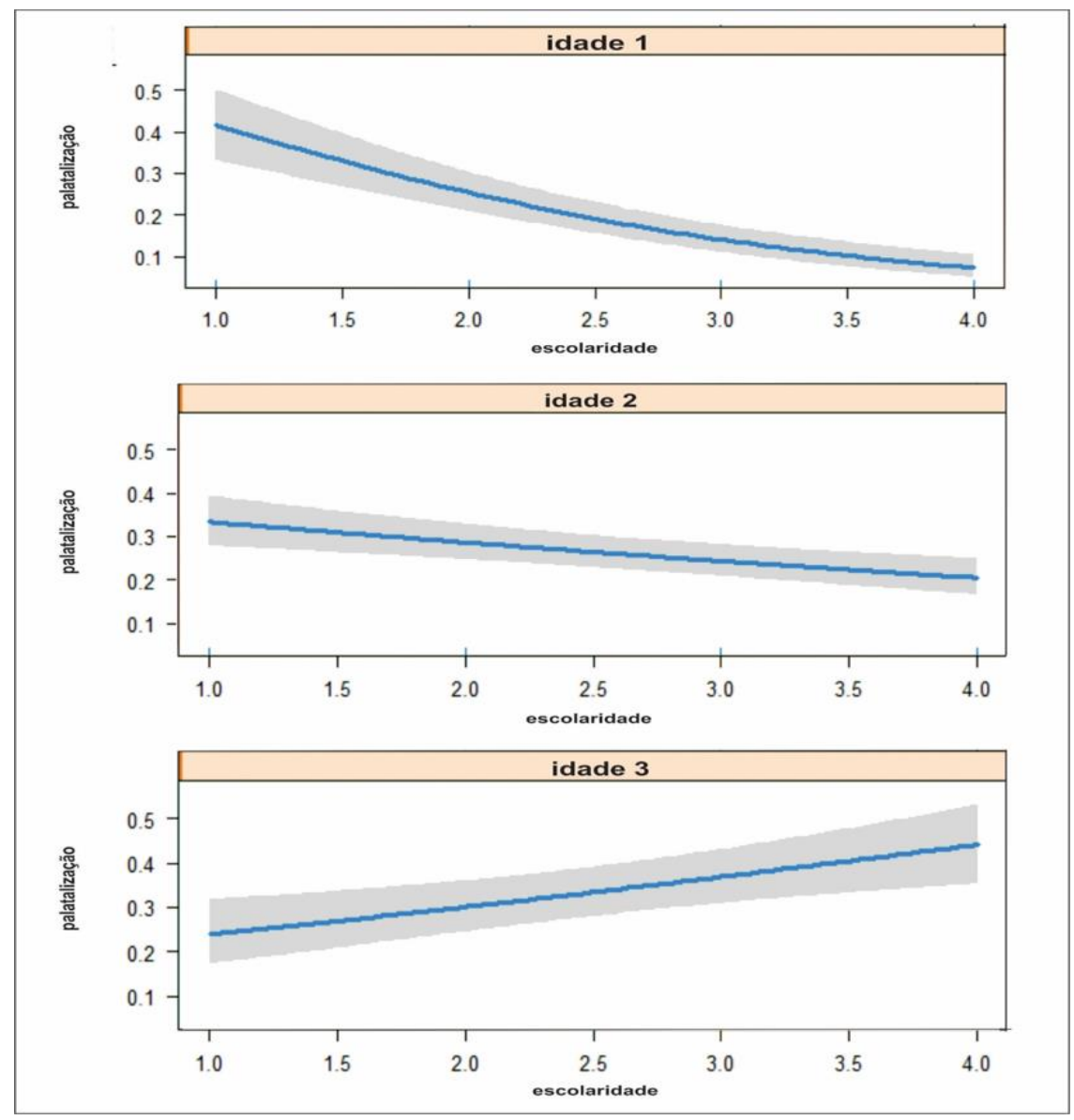

Figura 2: gráfico de palatalização das oclusivas alveolares e a interação entre idade e escolaridade. 
A figura 2 ilustra como o processo de palatalização das oclusivas alveolares em contexto de semivogal na cidade de Maceió é determinado pela interação entre idade e escolaridade, revelando que o comportamento do falante quanto ao seu nível de escolaridade depende, outrossim, da sua faixa etária, uma vez que os colaboradores mais jovens demonstram uma maior sensibilidade aos efeitos da escolarização. Ao se observar a probabilidade estatística dos mais jovens (idades entre 18 e 35 anos) produzirem as variantes palatalizadas de /t/ e /d/, tem-se um valor próximo de 0.4 , para o nível de baixa escolaridade - o maior valor de probabilidade para este nível de escolaridade - que apresenta leve distinção em relação às outras faixas etárias.

Em contrapartida, ao considerar os dados dos colaboradores dos demais níveis etários vê-se uma progressão linear inversa, uma vez que enquanto os mais jovens, com idade entre 18 e 35 anos, com ensino superior apresentam uma probabilidade inferior à 0.1 de favorecer o processo de palatalização; a segunda faixa etária, com idade entre 36 e 55 anos, apresenta uma suave alteração em desfavor do processo - conforme aumenta a escolaridade do colaborador - ficando entre 0.3 e 0.2 a probabilidade de realizações palatalizadas das oclusivas alveolares, respectivamente; e no grupo com a idade acima de 55 anos, tem-se um caminho inverso dos jovens, com uma progressão de favorecimento deste processo de palatalização, saindo de cerca de 0.3 para os colaboradores de baixa escolaridade e chegando a quase 0.5 quando o falante tem ensino superior.

Isto revela que a reação do falante à interferência da escolaridade depende da sua faixa etária, sendo uma evidência que este processo de palatalização das oclusivas alveolares em Maceió está adquirindo uma aparente marca social negativa e que a escola está exercendo a eficiente função de propagar as formas linguísticas de prestígio.

Os dados dos colaboradores da primeira faixa etária, com idade entre 18 e 35 anos, revelam evidências de uma maior sensibilidade dessa faixa etária às marcas sociais da escolarização, uma vez que há favorecimento da aplicação da regra de palatalização quando os dados são de jovens com maior nível de escolaridade. Em oposição, os dados de colaboradores mais velhos com os níveis mais baixos de escolarização demonstram clara inibição ao favorecimento da regra de palatalização das oclusivas alveolares.

Assim, fica claro que a interferência da escolaridade no processo de palatalização das oclusivas alveolares é inversamente proporcional em relação à idade do falante, que quanto 
mais velho, menos sensibilidade demonstra à valoração escolar das variantes palatalizadas e quanto menor a idade, mais sensível será à influência da escolarização.

De igual modo, os dados obtidos com a variável externa sexo sugerem um comportamento social distinto no processo de palatalização das oclusivas alveolares em contexto de semivogal, de modo que os membros do sexo feminino se mostram inibidores do processo, enquanto os falantes masculinos demonstram favorecimento das variantes palatalizadas ao apresentarem um índice de probabilidade de realização do processo de palatalização em 0.34 , em contraposição a 0.25 , do sexo feminino.

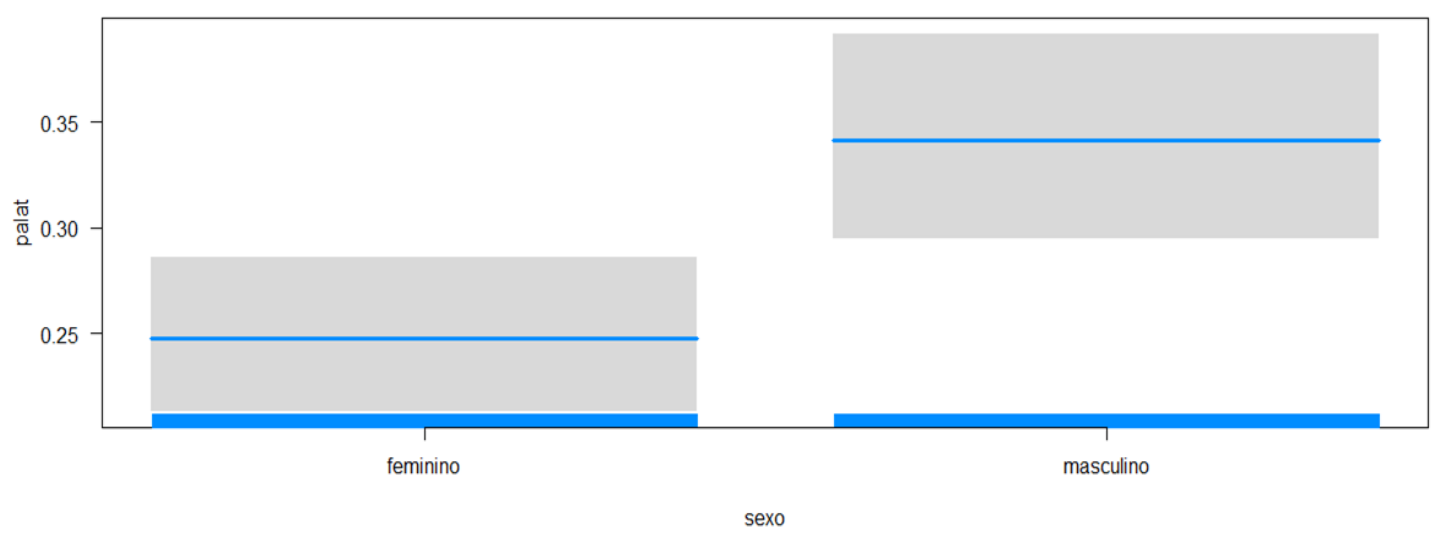

Figura 3: gráfico de palatalização das oclusivas alveolares e a variável sexo em um modelo com a semivogal [j] em contexto anterior às oclusivas.

Essa interferência da variável sexo no processo de palatalização das oclusivas alveolares fica ainda mais clara ao observar a disposição do percentual, do peso relativo e do p-valor, conforme se verifica na figura 4:

\begin{tabular}{cc|c|c|c|c}
\hline & Sexo & Apl./Total & $\%$ & Peso relativo & p-valor \\
\hline & masculino & $906 / 213$ & 23,5 & 0.55 & 0.000 \\
& feminino & $1141 / 205$ & 18,0 & 0.45 & 0.000 \\
\hline Total & & $2047 / 417$ & 20,4 & & \\
\hline
\end{tabular}

Figura 4: tabela de palatalização das oclusivas alveolares e a variável sexo em um modelo com a semivogal [i] em contexto anterior às oclusivas.

Conforme se verifica na figura 4, os homens aparecem como favorecedores do processo de palatalização das oclusivas alveolares em contexto de semivogal com peso relativo de 0.55 , enquanto as mulheres demonstram um comportamento inibidor das 
variantes palatalizadas e surgem com um peso relativo de 0.45 . Esses dados numéricos são evidências de que as variantes palatalizadas das oclusivas alveolares em contexto de semivogal, como em palavras do tipo "mui[t $]$ o" e "doi[d3]o" possuem alguma marca social negativa ao serem evitadas pelas mulheres e terem uma maior produção com os colaboradores do sexo masculino, corroborando o pensamento de Labov (1991) sobre como as escolhas linguísticas dos falantes podem ser afetadas pelo sexo:

A diferenciação estabelecida entre os sexos pode refletir-se no uso das formas de acordo com o sexo do ouvinte, bem como do falante. Estes informes qualitativos geralmente representam um dimorfismo sexual que é reconhecido por todos os membros da comunidade, estão disponíveis para uso, e são abertamente ensinados às crianças pelos adultos ${ }^{6}(\mathrm{LABOV}$, 1991, p. 210).

Para iniciar a análise das variáveis linguísticas, quanto a possíveis condicionamentos no processo de palatalização das oclusivas alveolares, é apresentada a figura 5, que ilustra a disposição das vogais do contexto seguinte às oclusivas alveolares em relação à variável dependente.

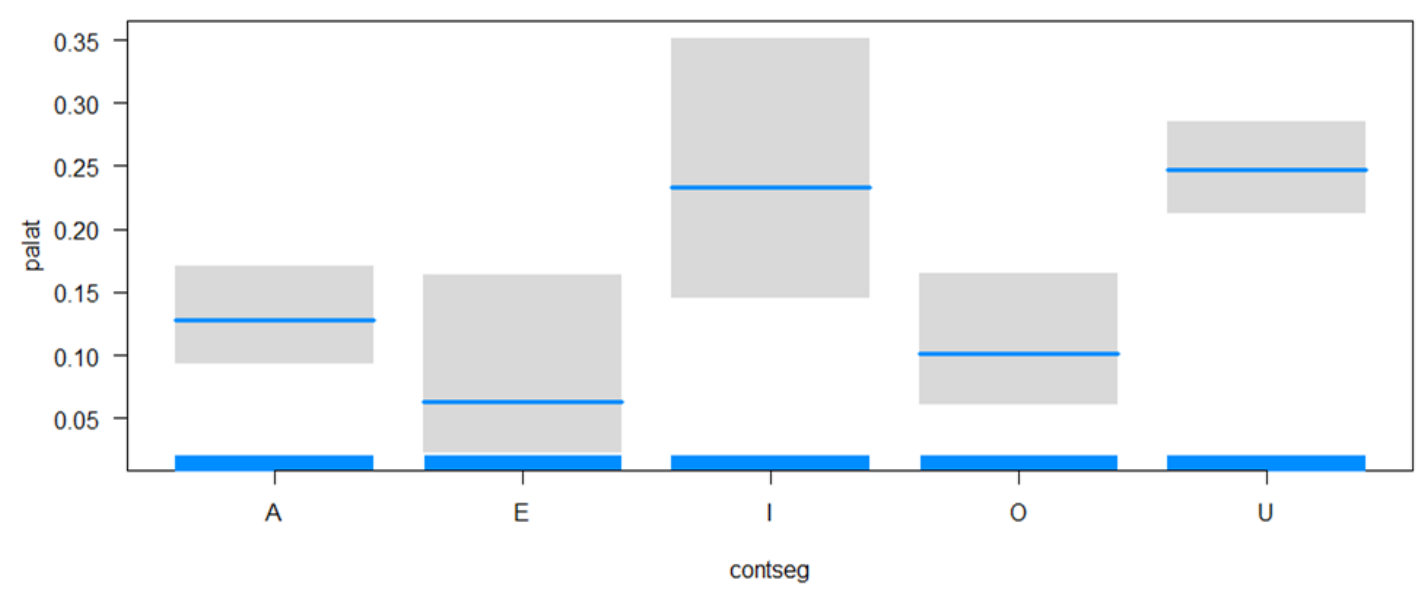

Figura 5: gráfico de palatalização das oclusivas alveolares e a variável contexto seguinte em um modelo com a semivogal [j] em contexto anterior às oclusivas.

Destacam-se, quanto ao condicionamento da palatalização das oclusivas alveolares em contexto de semivogal, as vogais altas /i/ e /u/, com índices de probabilidade de ocorrência das variantes palatalizadas entre 0.23 e 0.25 , respectivamente. A vogal média /e/

\footnotetext{
${ }^{6}$ No original: "Institutionalized differentiation of the sexes may be reflected in adjustment of forms according to the sex of the hearer as well as the speaker. These qualitative reports usually represent a sexual dimorphism that is recognized by all members of the community, is available for quotation, and is overtly taught to children by care takers".
} 
apresentou a menor probabilidade de favorecimento das variantes palatalizadas com índice de 0.07. A vogal média /o/ e a vogal baixa /a/ apresentaram valores de probabilidade em favor das formas palatalizadas das oclusivas alveolares entre 0.13 e 0.1 , inibindo, dessa forma o processo. A interpretação dos dados numéricos da variável contexto seguinte fica mais detalhada ao ter a distribuição total dos dados, o percentual, o peso relativo e o p-valor, conforme pode ser verificado na figura 6:

\begin{tabular}{|c|c|c|c|c|}
\hline Contexto seguinte & Apl./Total & $\%$ & Peso relativo & $\overline{p \text {-valor }}$ \\
\hline A & $460 / 53$ & 11,5 & 0.47 & 0.586 \\
\hline $\mathrm{E}$ & $168 / 6$ & 3,6 & 0.29 & 0.038 \\
\hline I & $206 / 27$ & 13,1 & 0.65 & 0.009 \\
\hline $\mathrm{O}$ & $44 / 4$ & 9,1 & 0.41 & 0.143 \\
\hline $\mathrm{U}$ & $1169 / 328$ & 28,1 & 0.67 & 0.000 \\
\hline Total & $2047 / 418$ & 20,4 & & \\
\hline
\end{tabular}

Figura 6: tabela da palatalização das oclusivas alveolares e a variável contexto seguinte em um modelo com a semivogal [j] em contexto anterior às oclusivas.

Conforme se verifica na figura 6 , as vogais /i/ e / $\mathrm{u} /$ apresentam os maiores valores de pesos relativos, confirmando um favorecimento à regra de palatalização das oclusivas alveolares em contexto de semivogal. A vogal /e/, por outro lado, é a que apresenta o menor valor de peso relativo, com 0.29 , desfavorecendo este processo de palatalização. As vogais /a/ e /o/ também apresentam um peso relativo abaixo do ponto neutro de 0.5 , o que pode sugerir um desfavorecimento do processo de palatalização, mas como são acompanhadas de altos índices de p-valor - acima de 0,05 - pode-se dizer que isto evidencia a não significância distintiva das variantes em relação ao ponto neutro, de modo que não há como atestar seguramente que esses fatores fonéticos estejam inibindo o processo de palatalização.

O ponto interessante do comportamento dessas variantes em relação à variável dependente, é que as vogais altas /i/ e /u/ se mostraram claramente favorecedoras do processo, enquanto as demais não, de modo que é possível assumir que no contexto de semivogal o processo de palatalização é favorecido se houver uma das vogais altas localizada após a consoante oclusiva. 
Quanto à análise da fronteira lexical no processo de palatalização das oclusivas alveolares em contexto de semivogal, fica evidente que o contexto de não fronteira favorece o processo de palatalização, ao passo que o contexto de fronteira o desfavorece, como ilustra a figura 7 :

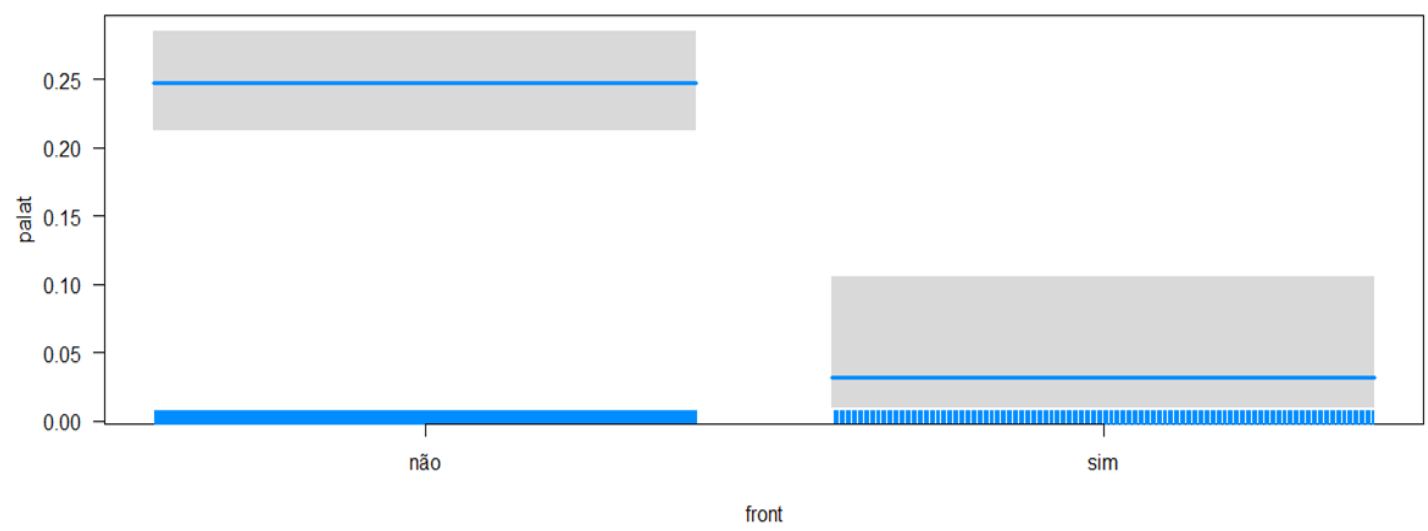

Figura 7: gráfico de palatalização das oclusivas alveolares e a variável fronteira lexical em um modelo com a semivogal [j] em contexto anterior às oclusivas.

Como está disposto na figura 7, a probabilidade estatística de ocorrer a palatalização das oclusivas alveolares em contexto de semivogal quando não se tem fronteira lexical é de 0.25 , claramente favorecendo o processo de palatalização. Por outro lado, em ambiente de limite de palavra lexical, o valor probabilístico de ocorrência de variantes palatalizadas é 0.03 , inibindo o processo.

\begin{tabular}{cc|cc|c|c}
\hline & Fronteira & Apl./Total & $\%$ & Peso relativo & p-valor \\
\hline \multirow{2}{*}{ sim } & $398 / 4$ & 1,0 & 0.20 & 0,000 \\
& não & $1649 / 414$ & 25,1 & 0.80 & 0,000 \\
\hline Total & & $2047 / 418$ & 20,4 & & \\
\hline
\end{tabular}

Figura 8: tabela de palatalização das oclusivas alveolares e a variável fronteira lexical em um modelo com a semivogal [j] em contexto anterior às oclusivas.

Os valores dispostos na figura 8 revelam que, embora o ambiente de fronteira lexical permita a ocorrência de formas palatalizadas, não é favorável ao processo, mas se comporta como seu inibidor ao apresentar peso relativo de 0.2. O contexto de não fronteira, por outro lado, configura-se claramente como favorecedor do processo e surge com peso relativo de 0.8 . 
A análise do vozeamento das consoantes oclusivas alveolares também revela que a sonoridade da consoante atua no processo de palatalização, favorecendo as variantes palatalizadas quando se tem a consoante desvozeada, enquanto que a presença da consoante vozeada se mostra inibidora do processo, consoante pode ser verificado na figura 9:

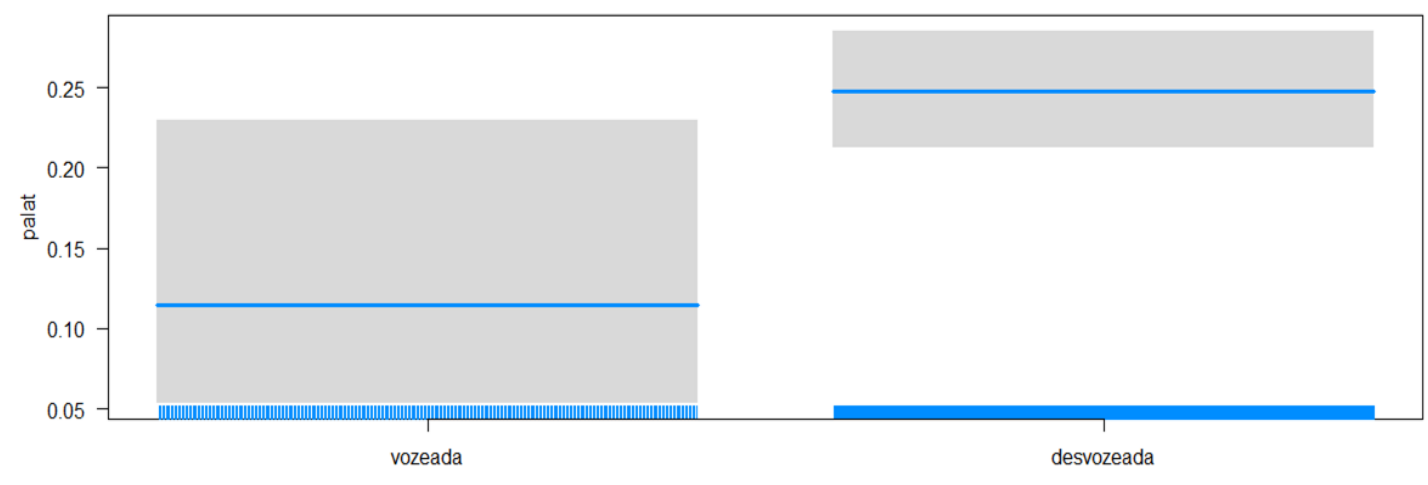

td

Figura 9: gráfico da palatalização das oclusivas alveolares e a variável vozeamento em um modelo com a semivogal [j] em contexto anterior às oclusivas.

Observando a disposição dos dados na figura 9, é notável como a consoante vozeada /d/ dificulta o processo de palatalização ao apresentar uma probabilidade de ocorrência de variantes palatalizadas de 0.12 , à medida que a consoante desvozeada promove o processo de palatalização com um valor probabilístico de 0.25 .

\begin{tabular}{cc|cc|c|c}
\hline & Vozeamento & Apl./Total & $\%$ & Peso relativo & p-valor \\
\hline \multirow{2}{*}{ vozeada } & $316 / 9$ & 2,8 & 0.39 & 0,034 \\
\multicolumn{1}{c|}{ desvozeada } & $1731 / 409$ & 23,6 & 0.61 & 0,034 \\
\hline Total & $2047 / 417$ & 20,4 & & \\
\hline
\end{tabular}

Figura 10: tabela de palatalização das oclusivas alveolares e a variável vozeamento em um modelo com a semivogal [j] em contexto anterior às oclusivas.

Os valores probabilísticos na figura 9 são confirmados na figura 10 ao trazerem tamanha desproporção percentual na realização das variantes palatalizadas de 2,8\%, quando se tem a consoante vozeada, contra $23,6 \%$, quando se trata da consoante vozeada. Tamanha desproporção acaba por resultar no peso relativo, que tem valores de 0.39 e 0.61 para as variantes vozeada e desvozeada, respectivamente, confirmando que na proporção que a consoante desvozeada propicia o processo de palatalização, a presença da consoante vozeada $\mathrm{o}$ inibe. 
Há aqui um favorecimento da consoante desvozeada [t] no processo de palatalização, provavelmente por motivações articulatórias, uma vez que esta consoante tem todos os seus segmentos realizados na região anterior da cavidade bucal, o que não acontece com sua equivalente vozeada [d].

Ao observar a relação entre o tamanho da palavra, em quantidade de sílabas, e o processo de palatalização das oclusivas alveolares, fica evidente como a quantidade de sílabas na palavra interfere no processo, no sentido de que quanto maior a palavra, maior a possibilidade de realizações palatalizadas. Para concretização dessa pesquisa, foram consideradas as palavras de uma a até quatro sílabas e todas que tinham cinco ou mais, de modo que o número 5 nos dados da figura 11 representa as palavras acima de quatro sílabas.

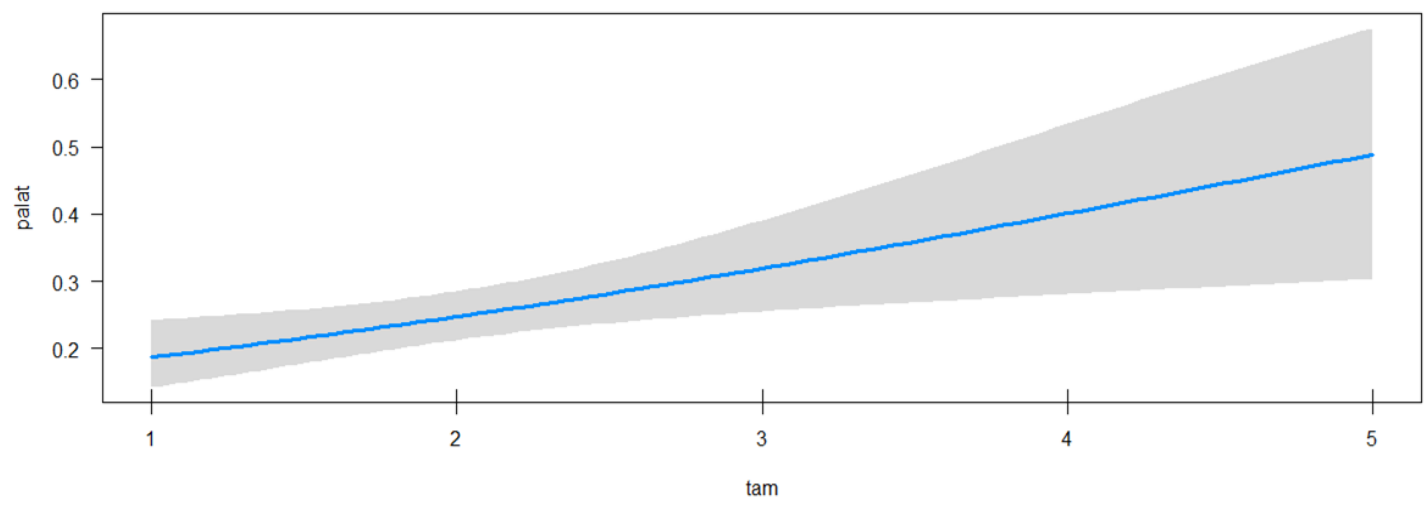

Figura 11: gráfico de palatalização das oclusivas alveolares e a variável tamanho de palavra em um modelo com a semivogal [j] em contexto anterior às oclusivas.

Apesar da alta faixa de dispersão, representada na figura 11 pela área acinzentada, há uma clara progressão linear no favorecimento do processo de palatalização conforme aumenta o tamanho da palavra, iniciando com as palavras monossílabas com um índice probabilístico de 0.2 e chegando a 0.49 com as palavras maiores, acima de quatro sílabas.

Como o tamanho da palavra se trata de uma variável contínua, significa esperar que sua distribuição seja sempre linear, em favor ou não do processo investigado. Por este motivo, o cálculo de peso relativo dá-se de modo diferente, surgindo não com valores que favoreçam ou inibam a aplicação da regra a partir de um ponto neutro de 0.5 , mas resulta em expressões numéricas que representam uma progressão a cada fator da variável contínua.

Neste caso, em se tratando da interferência do tamanho da palavra na regra de palatalização das oclusivas alveolares, o peso relativo foi de 0,09 , o que acarreta um valor 
progressivo a ser acrescido a cada sílaba que aumenta no tamanho da palavra, ou seja, às palavras monossílabas caberia um peso relativo 0.09, expressando claramente uma inibição ao processo; às palavras dissílabas, o peso relativo seria de 0.18 ; às palavras trissílabas, 0.27 ; às palavras de 4 sílabas, 0.36; e às palavras acima de 4 sílabas, o peso relativo seria de 0.45 , demonstrando um visível desfavorecimento do processo de palatalização conforme diminui o tamanho da palavra.

\section{Conclusão}

O principal objetivo desta pesquisa foi apresentar uma análise variacionista dos processos de palatalização das oclusivas alveolares em Maceió, com o intuito de investigar e descobrir as correlações linguísticas e sociais condicionantes do processo.

Considerando a correlação resultante da análise estatística dos dados entre o processo de palatalização das oclusivas alveolares com a semivogal [j] em posição de gatilho, as ilações podem ser as seguintes:

- O tamanho da palavra interfere no processo de palatalização, no sentido que quanto maior for, maior também será a possibilidade de haver palatalização;

- A variável acento não apresenta interferência no processo de palatalização;

- $\quad \mathrm{Na}$ posição de contexto seguinte às oclusivas, as vogais altas /i/ e /u/ são favorecedoras do processo;

- A interação entre idade e escolaridade é acentuada, demonstrando que o público mais jovem é bem mais sensível à interferência da escolarização na escolha das variantes linguísticas;

- O público feminino desfavorece a realização das variantes palatalizadas.

A tonicidade da palavra investigada em contexto da semivogal [j] em posição de gatilho demonstrou, em consonância com outros estudos sobre a palatalização progressiva (SANTOS, 1996; SOUZA NETO, 2014), o não condicionamento das variantes, sendo 
irrelevante para o processo de palatalização a tonicidade da posição silábica da consoante oclusiva.

Há uma aparente inovação ao processo de palatalização das oclusivas alveolares quanto ao contexto seguinte quando se tem a semivogal [j] em posição de gatilho, pois neste caso não apenas a vogal /i/ mostrou-se favorecedora das variantes palatalizadas, mas também a vogal / u/, o que revela que o traço +altura da vogal seguinte também está afetando o processo de palatalização.

A variável linguística vozeamento revela que a consoante desvozeada/t/, como esperado, favorece o processo de palatalização, ao passo que a consoante vozeada /d/ o restringe, possivelmente, porque no caso das consoantes vozeadas há o movimento das pregas vocálicas localizadas na laringe, sendo este um ponto de articulação distante da coroa da língua, que categoricamente tem favorecido os processos de palatalização em Língua Portuguesa.

De igual modo, a variável fronteira lexical revelou que embora seja possível a palatalização das consoantes oclusivas em palavras fonológicas que extrapolem os limites das palavras lexicais, sua realização é bastante limitada e sua produtividade é estatisticamente não significativa. Sendo, consequentemente, o fator de não fronteira mais significativo em ambos contextos de investigação. Os casos de fronteira lexical inibem a palatalização das oclusivas alveolares / t/ e /d/ porque necessitam previamente de um outro processo fonético, que é a elisão temporal das pausas que marcam as fronteiras lexicais para originar uma única palavra fonológica.

A interação entre as variáveis externas idade e escolaridade aponta que os efeitos da escolaridade sobre as escolhas das variantes linguísticas pelos falantes são mais intensos com colaboradores mais jovens, com idade entre 18 e 35 anos, condicionando-os a evitarem as formas palatalizadas e produzirem as formas oclusivas. Isso revela que as formas palatalizadas do tipo "oi[t] o" e "doi[dz]o" sofrem de aparente estigma social e que o ambiente escolar vem se tornando o grande fomentador deste aparente valor social negativo, sendo, portanto, maior sua influência entre os falantes mais jovens que frequentam ambientes educacionais. 
Os dados sociais apontam, de uma forma geral, para o enfraquecimento das variantes palatalizadas, uma vez que genericamente as pessoas mais jovens, mais escolarizadas e do sexo feminino tendem a evitar essas formas e a preferir os fones oclusivos.

A proposta fonológica para explicar o processo de palatalização das oclusivas alveolares é que há interferência dos traços [+coronal] e [+contínuo] - presentes no elemento fonológico anterior às oclusivas - na realização da consoante. A percepção é que ambos os traços, presentes neste contexto, funcionam em conjunto, como gatilho do processo, alterando o traço [-contínuo] da consoante seguinte, que afetada pela positividade do traço contínuo apresenta um comportamento misto, dando origem a uma metástase retardada, característica dos sons africados.

Portanto, através de um processo de contorno fonológico, as consoantes oclusivas alveolares /t/ e /d/, que possuem o traço [-contínuo], sofrem a assimilação do traço [+contínuo] do segmento anterior - quando há o compartilhamento do traço [+coronal] - e se transformam em consoantes africadas, caracterizando o processo de palatalização das oclusivas alveolares.

Sabendo que a discussão não está encerrada e que novos trabalhos se tornam necessários para retratar novos ângulos de observação para essa imagem, este artigo tem a pretensão de se tornar uma ferramenta para futuras pesquisas sobre o fenômeno da palatalização das oclusivas alveolares, em especial sobre a palatalização progressiva.

\section{Referências}

AQUINO, Jakson Alves. R para cientistas sociais. Ilhéus, BA: EDITUS, 2014.

CAMPOY, Juan Manuel Hernandez; ALMEIDA, Manuel. Metodología de la investigación sociolinguística. Granada: Editorial Comares, 2005.

CLARKE, Sandra. Language in Newfoundland and Labrador: past, present and future. Journal of the Canadian Association of Applied Linguistics v. 19, 1997, p. 11-34.

CRISTÓFARO SILVA, Thaïs et al. Revisitando a palatalização no português brasileiro. In: Revista de estudos linguísticos. Belo Horizonte, v. 20, nº 2, Jul./Dez. 2012, p. 59-89. 
ECKERT, Penelope. The meaning of style. Texas Linguistic Forum, n ${ }^{\circ} 47,2004$, p. 41 53. Disponível em: < https://web.stanford.edu/ eckert/PDF/salsa2003.pdf > . Acesso em: 7 de Jul. 2018.

GRIES, Stefan. Statistics for Linguistics with R: a practical introduction. 2 ed. Berlim; Nova Iorque: Mouton de Gruyter, 2013.

HENRIQUE, Pedro; HORA, Demerval. Um olhar sobre a palatalização das oclusivas dentais no vernáculo pessoense. Anais da Jornada do Grupo de Estudos Linguísticos do Nordeste, 24. Natal: EDUFRN, 2012.

LABOV, William. The intersection of sex and social class in the course of linguistic change. In: Language variation and change. V. 2. Cambridge: University Press, 1991, p. 205-254.

Padrões sociolinguísticos. São Paulo: Parábola, 2008 [1972].

MOLLICA, M. C.; BRAGA, M. L. Introdução à Sociolinguística: o tratamento da variação. São Paulo: Contexto, 2003.

MOTA, Jacira; ROLEMBERG, Vera. Variantes africadas palatais em Salvador. In: HORA, Demerval da. (Org.) Diversidade linguística no Brasil. João Pessoa: Ideia, 1997, p. 131-140.

NEUSCHRANK, Aline; MATZENAUER, Carmen Lúcia Barreto. A palatalização na diacronia do PB: o surgimento dos segmentos palatais à luz de teoria fonológica. In: Linguística. Montevidéu, v. 27, no 1, Jun. 2012, p. 18-46, jun. 2012. Disponível em: $<$ http:/ /www.scielo.edu.uy/scielo.php?script=sci_arttext\&pid=S2079-

312X2012000200003>. Acesso em: 7 de Jul. 2018.

OLIVEIRA, Almir Almeida de. Processos de palatalização das oclusivas alveolares em Maceió. Tese (Doutorado em Letras e Linguística). Maceió: Universidade Federal de Alagoas, 2017.

RONCARATI, Cláudia. Prestígio e preconceito linguísticos. Cadernos de Letras da UFF. Dossiê: preconceito linguístico e cânone literário, nº 36, $1^{\circ}$ sem. 2008, p. 45-56.

SANKOFF, David. Variable rules. In: AMMON, Ulrich; DTTMAR, Norbert; MATTEIR, Klaus J. (Org.) Sociolinguistics: an international handbook of the science of language and society. Nova Iorque: De Gruyter Mouton, 1988, p. 984-998. Trad. livre de Maria Marta Pereira Scherre. Brasília, 1992: revista em 1993, incorporando sugestões detalhadas de Ivone Isidoro Pinto (UFRJ), Maria Thereza Gomes Fiorett (UFRJ) e Maria Clara Álvares Correa Dias $(\mathrm{UnB})$.

SANTOS, Lúcia de Fátima. Realização das oclusivas /t/ e /d/ na fala de Maceió. Dissertação (Mestrado em Letras e Linguística). Maceió: Universidade Federal de Alagoas, 1996. 
SEVERO, Cristine. A comunidade de fala na sociolinguística laboviana: algumas reflexões. Voz das Letras, Revista da Universidade do Contestado, no 9, 2008, p. 1-17.

SOUZA NETO, Antônio Félix. Realizações dos fonemas /t/ e /d/ em Aracaju Sergipe. Aracaju: Editora UFS, 2014.

TARALLO, Fernando. A pesquisa sociolinguística. Série Princípios. São Paulo: Ática, 1997.

TRUDGILL, Peter. Language in the British isles. Cambridge: Cambridge University Press, 1984.

\begin{abstract}
This work aims to investigate the phonetic/phonological processes of progressive palatalization of the alveolar stops with a semivowel [j] in the previous context, as in words of the type oi $[\mathrm{t}]$ o and doi $[\mathrm{d}]]$, from the perspective of Variationist Sociolinguistics (LABOV, 2008 [1972]), produced in Brazilian Portuguese spoken in Maceió, contrasting the linguistic data collected as external variables (age, sex and schooling) and internal variables (following context, accent, word size, voicing and lexical border), in order to identify possible conditions of use of the variants. Using the bypothetical-deductive method, the obtained results point to the social interaction between social variables such as age and schooling, indicating that younger are the most favorable in this process of palatalization whenever they have low rates of schooling, whereas they present opposite linguistic behavior, inhibiting the palatalization, when there are more levels of schooling. Thus, there are signs that as palatalized forms suffer from a negative social valuation.
\end{abstract}

Keywords: Sociolinguistic Variationist. Palatalization. Maceió

Recebido em: 04/12/2017.

Aceito em: 03/07/2018 